\title{
DESIRABLE ATTRIBUTES OF AN EFFECTIVE INTELLIGENCE ANALYST
}

\author{
Željko Gajić, Zlatan Jeremić, Marija Stefanović \\ Ministry of Defense of the Republic of Serbia
}

The role of analytics in business and intelligence communities is more important than ever. The process of analyzing and evaluating a large quantity of data, as well as finding relations, trends, patterns and correlations is very complex. Processing a great amount of information and evaluating its reliability represents an additional problem. Bearing this in mind, preparing analysis is extremely difficult and requires high attention, trained personnel and application of modern scientific methods and techniques.

Key Words: intelligence, business analysis, Big Data, forecasting, decisionmaking

\section{Introduction}

T he process of globalization and fast developments in modern technologies available to various governmental institutions, non-governmental organizations and individuals have enabled a fast flow of information and increased the data availability. In addition, there has been an increase in the quantity of data that are generated worldwide with different contents and formats passed on via web pages, blogs, social networks, etc. The complexity of topics, contents, formats, scope and quantity of data have created new problems for analysts that could be solved only if the existing methods and techniques would be adjusted to new conditions. Moreover, analysts should be prepared to assess validity, select and process the data in an adequate manner, make analysis and create forecast. It means that selection of analysts and their later career development (training, education, career management, etc.) require taking these changes and new circumstances into consideration.

This problem is present both in business and intelligence communities. The modern security and business environment is affected by emergence of new, non-traditional and non-state actors, who take advantage of benefits of modern time and tend to create a more unstable and unclear situation. Reduction of uncertainty in those circumstances is a very difficult task, which is the reason why both the intelligence and business communities are trying to find a way to improve understanding of important actors, events and processes.

The dynamic environment and an increasingly unstable and competitive situation stimulate intelligence analytics to find new methods and tools for increasing confidence in their product by providing timely and accurate analysis for decision-makers. 


\section{Contemporary Analyst Environment (PN)}

Modern business conditions contribute to faster development of some disciplines that should be able to offer an answer based on scientific principles regarding the issue of how to make a business decision with less risk. Development of business analytics is very important to this end as it includes the opportunities of informational technologies, the demands of managers and the challenges of making business both at present and in the future.

There is a growing trend in business environment that requires analytical competencies and skills in jobs at using a large quantity of data. These analytical jobs are being more and more paid. According to the annual Glassdoor research, a list of the best paid jobs in the U.S. has been made on the basis of a few criteria such as income, a number of vacancies and content of employees at workplaces. The second year in a row the best ranked job is the one of Data Scientist, and the high ranking ones on the list of the best paid jobs are also analytical jobs (Data Engineer, Analytics Manager, Solutions Architect, Intelligence Analyst, Security Analyst) (1). However, the trend of high demand for analysts in the market has also resulted in the problem for organizations and institutions to provide the necessary number of high quality analysts. The labor market registers the lack of Data Engineers. Therefore, $40 \%$ of the companies involved in the poll invest great effort to find and keep the experts in this field (2). According to the research conducted by the company MGI, by 2018 there would be the lack of 140.000 to 190.000 persons with the special analytical skills and some 1.5 million managers and analysts with the knowledge of management and usage of a great number of data for supporting decisionmaking at the labor market (3). Due to work specificity, the analytical jobs in the US Intelligence Community are numerous, and analysts are highly demanded. Former US Intelligence Community Director James Clapper believes that it will be, for various reasons, more and more difficult to attract young people to work in the intelligence agencies (4).

The aforementioned confirms the fact that the number of jobs which require general and specific analytical knowledge and skills will increase and that the demand for experts with analytical skills will grow in the upcoming period.

\section{Power of Business Analytics}

The increase in amount of information is generated nowadays in an electronic form. The explosive rate of data growth and variety of information represents a great challenge. Transactional data (financial and business), environmental data (captured by many sensors), geospatial data, scientific results, different types of news and diverse public data are available to customers. They are presented in various types as texts, images, audio and video and can be found on the web, social networks, cameras and other devices (5). GPS coordinates generated by smart devices and data provided by the devices equipped with various remote control sensors (Internet of Things) enable us to have easier and simpler life, but at the same time contribute to a huge increase in an amount of electronic data. This phenomenon is known as Big Data (6). 
Due to private sector interests, a great progress in processing and analyzing data has been achieved. Commercial sector makes use of new technologies' potential, especially in monitoring customers' behavior and consuming routines. On the basis of sophisticated algorithm and advance software, a marketing expert can explore, analyze, explain and provide understanding of customers' behavior and consumption pattern. As a result, they can predict customers' wishes, suggest appropriate approach to a client and prepare customized offers.

Business analytics is now more affordable for common use than ever before. The usage and analysis of a large quantity of data is not the field dealt with by scientists anymore, but it now represents the possibility available to analysts and managers in companies. The evolution of business data into the cloud has started and there is less need for big capital investments in servers, dedicated software, support and maintenance, which makes a powerful financial argument (7). The development of voice interface can help customers minimize the need for programming, traditional querying and reporting tools, complex filters and algorithms in order to analyze data. According to Zion Market Research, the value of business intelligence market in 2015 accounted USD 16.33 billion and is expected to rise by an annual rate of $8.4 \%$ in order to reach USD 26.5 billion by 2021 (8).

Thus, the development of modern manager-oriented tools intended for processing of a great amount of data enables faster decision-making for businesses and secures better positions versus their competitors.

\section{The Role of a Modern Analyst}

The modern intelligence analytics is expected more than ever before to recognize in a large quantity of data the confirmed ones and those of quality and to put them in a wider context, relate them to the existing knowledge and timely prepare analysis and estimates that should help making the right decisions. Due to fast and difficult-to-predict changes, various forms of the existing threats and emergence of new ones, this job tends to be harder and it is not possible to solve it only by use of classical methods.

Intelligence analysts participate and have a great role in decision-making process but in a way that they are the decision-makers themselves. Analytics is a continuous process of opinion creation based on available but incomplete information on complex problems and phenomena. Analysis and estimates of events that are yet to happen make up the basis for decision-making (9). Political forecasting is very complicated and without ability to generate prediction by which we could neither interpret the past nor plan the future (10).

Better results can be achieved, as well as more objective analysis and more accurate estimate of probability by combination of several intelligence disciplines and exchange of information with different organizational units and agencies. Unknown details or hard-tonotice processes are more obvious if different data are analyzed from the early stages of the intelligence cycle and if analysts with different knowledge and skills are involved, who can contribute to creation of a clearer picture of the current and future developments. As the large quantity of data processing approach has changed, the importance of setting priorities, more precise direction and involvement of analysts with different competencies into making complex analytics products has grown. The various data integration skills offer an opportunity for important processes to follow up in an appropriate manner and register the changes that may represent potential threat in early stages. 


\section{Analyst Key Challenges}

In modern conditions, analysts face many old and new challenges that are the consequence of the changed circumstances. Two basic problems that analysts traditionally face are that they need to perceive the problem from the point of view of a customer, their needs and expectations and to be aware of some risks during preparing and writing analysis or oral briefings (11). A particular problem is making analysis from the domain of national security because they are done in complex conditions with limited number of credible data, often faced with disinformation and attempts at deception (12). Fast and hard-to-predict changes impose in almost all areas of life greater demands on analysts and make production of analysis, in particular estimates, more difficult.

\section{Consumers Needs and Expectations}

Information customers are nowadays more demanding and up-to-date and have a range of possibilities of choosing a piece of information, but also confirming the quality of analysis.

Rapid technology developments available to everyone enable customers to have an approach to a wide range of information, and great competitiveness of information of media, specialized agencies, various governmental and non-governmental organizations impose high standards for intelligence analysts. Customers and their requests are constantly changing, which is the reason why analysts should establish and keep the integrity for each of them (13). Intelligence consumers seek a more in-depth analysis, whose focus is on methodology, assumption and forecast. Providing a high level of credibility of an analytical product in the eyes of customers is a long-standing goal (14). There is a higher degree of competitiveness between private companies and agencies, which offer collecting and processing data services.

On the other hand, customers often form an opinion as all other people do: based on media and publicly available reports that are not always reliable and usable without additional analysis and check. The former CIA employee M. Petersen thinks that policymakers do not often understand intelligence mission, values or standards and tend to be skeptical, especially if they are new in that world (13).

\section{Big Data Challenges}

Besides the possibilities of better follow-up to interesting processes, a great rise in quantity of data has brought up additional problems in identifying the key parameters changes. The US Defense Intelligence Agency (DIA) Director General Vincent Stewart thinks that we have more data than we can process and it makes decision-making more difficult (15). Some data are available to other users and a significant part of data is of suspicious value, hard to check and thus of small value. During collection and processing of a great quantity of data it is necessary to check and select them a few times at different levels. It is possible that some data contain informative value but do not seem interesting or usable at that point, so they may be ignored, i.e. the necessary attention may not be paid to them (16). A special problem is the possibility to fabricate data and place them intentionally in order to create confusion and make 
taking an objective view on some event or phenomenon more difficult. Integration of various information systems, data bases and communication channels enables an unauthorized approach and distortion of gathered data and its own data, which imposes the need for the system protection and constant check and verification of information. From 2006 to 2015 a number of security incidents directed at the US governmental institutions information systems has been increased by more than ten times (17).

Therefore, an ability of modern analysts to take part in collecting, assessing and using available data and preparing information is of crucial importance in decision-making process. Analysts who possess great knowledge about specific or various areas together with those who can use and process a few types of information, identify trends and contribute with new insights by the application of advanced methods, techniques and modern technological solutions are the key to progress in making high quality analytical products in modern conditions (18).

\section{Modern analytical techniques}

A set of techniques known as Structured Analytic Techniques was developed for the needs of the US Intelligence Community, i.e. for making timely, reliable and high quality analytical products. This was the response to modern circumstances (complex environment, incomplete information, bias, various limitations, etc.) and unwonted intelligence failures (19) and (20). Authors emphasize that the application of techniques does not guarantee the accuracy of information, but it increases the reliability and quality of estimates, and therefore has a higher value for users. Techniques are grouped into the following three categories: diagnostic techniques used for hypothesis setting, contrarian techniques for application of critical thinking and imaginative thinking that develops new views on problems and possible scenarios (21).

The very techniques and their application are often taught at specialized courses. However, their application and how they can be used on real problems depends on abilities of analysts to apply them in real situation and current condition like limited available time. Decision-makers strive to have more time to decide, so that analysts are pressured to produce information as soon as possible (22). The process of initial analysis, analyst coordination and synchronized application of different techniques, as well as production and correction of output analysis, require time that is often longer than users expect. Making decisions in situations when it is necessary to react quickly implies the urgent preparation of analytical products, and then it is not possible to use all the available techniques unlike the situation when there is no such time limit. When the deadline is too short for the complete application of one or more techniques, Peterson proposes the use of five basic techniques (The Five Habits), whose application can help reach the response results in a shorter time (23).

\section{Standards}

In order to examine the desirable skills and knowledge of analysts, several institutions and authors have sought to establish the standards required to define the necessary competencies of analysts. The most common standards for research and analysis are the standards of the US intelligence community. 
Major changes in this area have been created on the basis of the Intelligence Reform and Terrorism Prevention Act (IRTPA) after the terrorist attack in the United States in 2001. One of the newer standards of analysis in the intelligence community is the Intelligence Community Directive (ICD) 203 of 2015 (24). The Directive defines the process of managing and evaluating analytical products, as well as the competencies and responsibilities of the participants. This directive represents the basic guidelines and principles of intelligence analytics used in the US intelligence community.

Office of the Director of National Intelligence has published several standards defining the necessary characteristics of analysts, which are covered by the Intelligence Community Directive No. 610. The analyst characteristics are detailed in ICS 610-3 (Core Competencies for Non-Supervisory Intelligence Community Employees); ICS 6104 (Core Competencies for Supervisory and Managerial Intelligence Community Employees); ICS 610-5 (Core Competencies for Intelligence Community Senior Officers) and ICS 610-7 (Analysis and production) (25). The mere existence of standards does not guarantee their comprehensive implementation because there is no body that has the authority to control their implementation. Most agency managers are more interested in improving existing procedures for the production of information than for the long-term and comprehensive professionalization of the analytical process (26).

A high-quality comparative analysis of the character of an analyst of the American intelligence community and the Association of American Colleges and Universities was presented by Kaspar, which shows that there is a high degree of correlation between them (27). There are also the views of other authors, who emphasize that existing standards do not respect changes that occur and do not take into consideration circumstances from the end of the twentieth century (28).

\section{Characteristics of a modern analyst}

In discussions on desirable characteristics of intelligence analysts, a comprehensive overview of basic abilities, knowledge and skills was presented by authors Moore and Krizan (29). The offered model shifts the focus from the previous consideration of analytics as an activity, process or organizational unit to the analysts themselves and their basic competencies. The authors have identified three abilities, eight skills and five types of knowledge that are desirable for a successful analyst.

In subsequent studies, the necessary levels of individual skills, knowledge and skills for various forms of analytical process were analyzed in detail, and more comprehensive linkage and harmonization were performed. This is particularly important in circumstances, where due to a large number of available information, it is necessary to verify, select, process, prepare and present analyses that satisfy the needs of increasingly demanding users. Ideally, analysts should dispose of all these characteristics, but in practical terms it is important to identify more precisely the necessary skills for certain types of analytical work. The acknowledged expert Moor has established these links and proposed minimum standards for describing, explaining, interpreting and estimating analytics (30).

Based on this, it can be concluded that certain characteristics are more significant for some types of analytics and knowledge and skills can be improved in direction towards future needs, i.e. career development plans and advancement of analysts. In descriptive 
analytics, special attention is paid to the skills of collecting, selecting and processing data. Good organization of work, as well as knowledge of searching and processing techniques of a large number of different types of data, is also important. Analysts, who work in explanatory analytics, need to establish certain patterns and monitor the ongoing changes in their topics, which is the reason why they need to work more with others. For them, the ability to work in a team, as well as knowledge of internal procedures and functioning of data collection and processing, were important. In the case of interpretive analytics, which should answer the question "what is happening", in addition to the use of known structural techniques, the intuition of analysts comes to expression. In addition, for the preparation of analyses of this type, great intellectual effort and cooperation with others is needed, which requires both good communication skills and great knowledge of the field of analysis. Making estimates represents the highest level of analytical work, and the estimates themselves are key analytical products that enable decision-makers to make the most important decisions. Therefore, it is very important to recognize the needs of users, the capacities and activities of other participants, and in cooperation with others, prepare and present various scenarios and possible consequences. Due to the significance of the analytical products themselves, as well as the need to engage analytics and other organizational units in accordance with the procedures and interests of customers, they need to be well aware of the policies, plans, constraints and agency capacities and the intelligence community as a whole.

\section{An Analysis of Analyst Job Description}

The results of the research conducted in Australia with the aim of establishing what employers consider necessary for the analytical workplaces are interesting (31). To this end, they analyzed over 300 public announcements (from 2009 to 2015, 45 different state agencies in Australia) for intelligence analyst jobs, paying particular attention to the required qualities.

The main role of analysts is to analyze data and prepare various analytical products for decision-makers. Types of data analyzed differ in relation to the business environment and the purpose of the analysis, so that the required characteristics differ in part. The authors believe there are no universally accepted standards, which are the required qualities, but they are based on the assumption that analysts need to be educated, know well the area they are dealing with, have the ability to solve a problem and have the ability of written and verbal expression.

According to research results, advertisers are expected to seek the university education, experience in intelligence analysis, management and information management. When it comes to the necessary knowledge, the greatest attention in advertisements is dedicated to knowledge of intelligence principles and practice, state administration and knowledge of the area in which the analysis is carried out. Knowledge of analytical methods and research techniques is much less interesting for employers, as this is probably the subject detailed in the job training. Among the necessary skills, the most wanted ones are the persons with expressive communication, analytical and research skills. Computer skills, organizational and leadership skills are much less sought after. As far as personal qualities are concerned, integrity and initiative are more respected and flexibility and productivity less. 


\section{Difficulties in achieving analyst full potential}

Analysts in contemporary conditions can, in addition to other important factors, contribute to significantly better positioning of companies in the modern business environment. The changing business environment and the expansion of the amount of various data generated in various forms and platforms make analysts more difficult to work and at the same time create many problems, but they also offer enormous potential and opportunities. However, the success of overcoming these problems depends on the ability of analysts to adapt to new circumstances, as well as to the attitude and activities of leaders in relation to the role of analytics. According to the estimates by the famous McKinsey agency in 2011, the EU member states could cut costs by $15-20 \%$ and save over 100 billion euros by increasing efficiency, transparency and using the potential of processing large amounts of data by 2021 (3). In the new report from 2016, it is concluded that 10 to $20 \%$ of the potential is used in regard to this issue. The main reasons are the complexity of the existing administrative system in the EU, as well as the problems in providing high quality and talented analysts (32). Therefore, in order to successfully fulfill the existing potentials, it is necessary, in addition to investment in technological solutions, to carry out the required organizational changes and select, prepare and adequately motivate analysts with the necessary knowledge and skills.

\section{Conclusion}

In modern conditions, technology plays a significant role in the process of collecting and processing data, as well as producing analytical products. The multiplicity and variety of data available to analysts enable the production of timely, accurate and quality information. However, the full potential of technology and the environment "enriched" with various data imposes the need to adjust existing procedures and modify known methods and techniques. Analysts who need to quickly adopt new technologies and apply their capabilities are very important in these processes. Being aware of the required characteristics, knowledge and skills of individuals working on various analytical tasks is important for the proper selection, training and career advancement of analysts. The famous author Heuer emphasized the importance of improving analytical abilities, but also warned that if the attention is not paid to the quality, the precision of analytic products will be reduced, and occasionally greater intelligence failures should be expected (33).

In the modern business and intelligence environment characterized by rapid changes and abundant information, it is possible to create the conditions for analyses to contribute to making better decisions and creating new values only with the appreciation of the increasing importance of analytical process and the ability of analysts. Organizations that recognize this trend and adapt their business processes and procedures will be in a better position than those who do not accept the possibilities that new technologies bring with them. In a creative atmosphere, talented and motivated analysts, who have good knowledge of the field of analysis and who recognize the needs and expectations of the customers, can, using appropriate techniques, prepare timely and accuracy information.

Data mining, Machine learning, Data Visualization, Artificial Intelligence can help in overcoming many of those issues, but what is and will be crucial is the role of humans with knowledge, abilities, skills and passion to find appropriate methods how to avoid traps and utilize the opportunities, which the new era brings. 


\section{Bibliography}

[1] Best Jobs in America [Internet]. Glassdoor. [cited 2017 Mar 27]. Available from: https://www.glassdoor.com/List/Best-Jobs-in-America-LST_KQ0,20.htm

[2] A Shortage of Talent in Data Analysis [Internet]. business.com. [cited 2017 Apr 19]. Available from: https://www.business.com/articles/big-data-big-problem-coping-with-shortage-of-talentin-data-analysis/

[3] Manyika J, Chui M, Brown B, Bughin J, Dobbs R, Roxburgh C, et al. Big data: The next frontier for innovation, competition, and productivity | McKinsey \& Company [Internet]. 2011 [cited 2017 Apr 19]. Available from: http://www.mckinsey.com/business-functions/digital-mckinsey/ourinsights/big-data-the-next-frontier-for-innovation

[4] Tim Johnson. U.S. spy agencies worry intrusive policies, pot ban hurt efforts to recruit young people [Internet]. McClatchy DC Bureau. [cited 2017 Jul 8]. Available from: http://www.mcclatchydc.com/news/nation-world/national/national-security/article146975044.html

[5] Nicolaus Henke, Jacques Bughin, Michael Chui, James Manyika. The Age Of Analytics: Competing In a Data-Driven World [Internet]. McKinsey Global Institute; 2016 Dec [cited 2017 Jul 16]. Available from: http://www.mckinsey.com/business-functions/mckinsey-analytics/our-insights/the-age-of-analyticscompeting-in-a-data-driven-world

[6] Steve Perry. What is big data? More than volume, velocity and variety... [Internet]. The developerWorks Blog. 2017 [cited 2017 Jul 25]. Available from:

https://developer.ibm.com/dwblog/2017/what-is-big-data-insight/

[7] Pepijn D. How business intelligence can help non-techies use data analytics [Internet]. The Next Web. 2017 [cited 2017 Jul 17]. Available from:

https://thenextweb.com/contributors/2017/07/11/business-intelligence-can-help-non-techies-usedata-analytics/

[8] Business Intelligence Market Size \& Share Worth Over USD 26.50 billion by 2021 - Money Panorama [Internet]. Money Panorama. [cited 2017 Jul 17]. Available from:

http://moneypanorama.com/101096/business-intelligence-market-size-share-worth-over-usd-2650-billion-by-2021/

[9] Charles Vandepeer. Applied Thinking for Intelligence Analysis - A Guide for Practitioners [Internet]. Air Power Development Centre, Department of Defence, Australia; 2014 [cited 2017 Mar 12]. Available from: http://airpower.airforce.gov.au/Publications/Details/590/Applied-Thinking-for-Intelligence-Analysis--AGuide-for-Practitioners.aspx

[10] Mellers B, Stone E, Atanasov P, Rohrbaugh N, Metz SE, Ungar L, et al. The psychology of intelligence analysis: drivers of prediction accuracy in world politics. J Exp Psychol Appl. 2015 Mar;21(1):1-14.

[11] Bruce J. Analyst, Thought Leader, Teacher Extraordinaire. Stud Intell. 2016;60(3):13.

[12] Dr. William L., Mitchell. The Art of Deception and the Role of Intelligence Education. In Atlanta; 2016 [cited $2017 \mathrm{Jul}$ 25]. Available from:

ttps://pure.fak.dk/ws/files/5985901/MAIN_PAPER_ATLANTA_2016_FINAL_Draft.pdf

[13] Petersen M, Lukes I, Ehrman J, Peake $\mathrm{H}$. What I Learned in 40 Years of Doing Intelligence Analysis for US Foreign Policymakers. Cent Intell AGENCY Wash DC Cent STUDY Intell [Internet]. 2011 [cited 2016 May 7];55(1). Available from:

http://oai.dtic.mil/oai/oai?verb=getRecord\&metadataPrefix=html\&identifier=ADA540669

[14] Anne Daugherty Miles. The U.S. Intelligence Community: Selected Cross-Cutting Issues [Internet]. Congressional Research Service; 2016 Apr [cited 2016 May 7]. Available from: https://www.fas.org/sgp/crs/intel/R44455.pdf

[15] DIA Leaders Discuss Innovation, leadership at Senior Military Intellig [Internet]. Defense Intelligence Agency. [cited $2017 \mathrm{Jul}$ 9]. Available from:

http://www.dia.mil/News/Articles/ArticleView/tabid/11448/Article/1229321/dia-leaders-discussinnovation-leadership-at-senior-military-intelligence-confe.aspx 
Desirable Attributes of an Effective Intelligence Analyst

[16] Friedman JA, Zeckhauser R. Assessing uncertainty in intelligence. Intell Natl Secur. 2012;27(6):824-847.

[17] Cooney M. Feds' primary network security weapon needs more bang [Internet]. Network World. 2016 [cited 2017 Jul 10]. Available from:

http://www.networkworld.com/article/3027635/security/dhs-gao-feds-primary-network-securityweapon-needs-more-bang.html

[18] Treverton GF, Gabbard CB. Assessing the tradecraft of intelligence analysis. Santa Monica, Calif: RAND Corporation; 2008. 54 p. (Technical report).

[19] Moore DT. Sensemaking: a structure for an intelligence revolution. Washington, DC: National Defense Intelligence College Press; 2011. 195 p. (Clift series on the intelligence profession).

[20] Cake Timothy. America's Alleged Intelligence Failure in the Prelude to Operation Iraqi Freedom: A Study of Analytic Factors [Internet] [A Dissertation Submited for PhD]. Universityof Calgary; 2017. Available from: http://hdl.handle.net/11023/3688

[21] U.S. Government. A Tradecraft Primer: Structured Analytic Techniques for Improving Intelligence Analysis. CIA Cent Study Intell [Internet]. 2009 [cited 2017 Mar 12]; Available from: http://cm.1-s.es/ admissions/10-2014/cia-tradecraft-primer-2009.pdf

[22] Charles Vandepeer. Question-Asking in Intelligence Analysis. ASPJ Afr Francoph [Internet]. 2016 [cited 2017 Mar 12];4 th Quarter 2016. Available from:

http://www.au.af.mil/au/afri/aspj/apjinternational/aspj_f/digital/pdf/articles/2016_4/vandepeer_e.pdf

[23] Pherson R. The Five Habits of the Master Thinker. J Strateg Secur. 2013 Oct;6(3):54-60.

[24] Office of the Director of National Intelligence. Intelligence Community Directive (ICD) 203 Analytic Standards [Internet]. 2015 [cited 2017 Jul 17]. Available from:

https://www.dni.gov/files/documents/ICD/ICD\%20203\%20Analytic\%20Standards.pdf

[25] Director of National Intelligence - Intelligence Community Directives [Internet]. [cited 2017 Jul 16]. Available from: https://fas.org/irp/dni/icd/

[26] Bruce J, George R. Professionalizing Intelligence Analysis. J Strateg Secur. 2015 Sep;8(3):1-23.

[27] Kaspar WA. Information Survival Skills for Students in Intelligence Studies and International Affairs. In Austin, TX, United States; 2014 [cited 2017 Mar 12]. Available from: http://web.isanet.org/Web/Conferences/ISSS\%20Austin\%202014/Archive/695023c0-10b5-481cb625-22c442428931.pdf

[28] Landon-Murray M, Coulthart S. Academic Intelligence Programs in the United States: Exploring the Training and Tradecraft Debate. Glob Secur Intell Stud [Internet]. 2016 [cited 2017 Mar 12];2(1). Available from: http://www.ipsonet.org/publications/open-access/gsis/gsis-volume-2-number-1-fall-2016

[29] Swenson RG. Bringing intelligence about: Practitioners reflect on best practices [Internet]. Joint Military Intelligence College; 2003 [cited 2017 Mar 12]. Available from:

www.au.af.mil/au/awc/awcgate/dia/bring_intel_about.pdf

[30] Moore DT. Species of Competencies for Intelligence Analysis. Am Intell J. 2005;ja:29-43.

[31] Corkill JD, Cunow TK, Ashton E, East A. Attributes of an analyst: What we can learn from the intelligence analysts job description. In Perth, Western Australia; 2015 [cited 2017 Jul 10]. (Australian Security and Intelligence Conference). Available from: http://ro.ecu.edu.au/asi/42

[32] The need to lead in data and analytics | McKinsey \& Company [Internet]. [cited 2017 Jul 16]. Available from: http://www.mckinsey.com/business-functions/digital-mckinsey/our-insights/the-need-tolead-in-data-and-analytics

[33] Heuer RJ. Psychology of intelligence analysis. Washington, D.C.: Center for the Study of Intelligence, Central Intelligence Agency; 1999. 184 p. 